\title{
Structural changes arising from different thawing protocols on cryopreserved human allograft's aortic valve leaflets
}

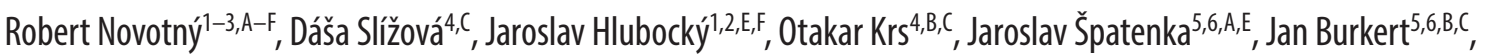 \\ Radovan Fiala ${ }^{6,7, B}$, Petr Mitáš ${ }^{1,2, D, E}$, Pavel Měricka ${ }^{8, E, F}$, Miroslav Špaček ${ }^{1,2, B}$, Zuzana Hlubockáá, 2,8, E, Jaroslav Lindner ${ }^{1,2, A, F}$ \\ ${ }^{1} 2^{\text {nd }}$ Department of Cardiovascular Surgery, General University Hospital, Prague, Czech Republic \\ ${ }^{2} 1^{\text {st }}$ Faculty of Medicine, Charles University, Prague, Czech Republic \\ ${ }^{3}$ Transplant Surgery Department, Institute for Clinical and Experimental Medicine, Prague, Czech Republic \\ ${ }^{4}$ Department of Anatomy, Faculty of Medicine, Charles University, Hradec Králové, Czech Republic \\ ${ }^{5}$ Transplant Center, University Hospital Motol, Prague, Czech Republic \\ ${ }^{6}$ Department of Cardiovascular Surgery, Faculty Hospital Motol, Prague, Czech Republic \\ ${ }^{7} 2^{\text {nd }}$ Faculty of Medicine, Charles University, Prague, Czech Republic \\ ${ }^{8}$ Tissue Bank, Faculty Hospital Hradec Králové, Faculty of Medicine, Charles University, Czech Republic \\ ${ }^{9} 2^{\text {nd }}$ Internal Department of Cardiology and Angiology, General University Hospital, Prague, Czech Republic \\ A - research concept and design; $\mathrm{B}$ - collection and/or assembly of data; $\mathrm{C}$ - data analysis and interpretation; \\ $D$ - writing the article; $E$ - critical revision of the article; $F$ - final approval of the article
}

\section{Address for correspondence}

Robert Novotný

E-mail: novotny_robert@hotmail.com

Funding sources

None declared

Conflict of interest

None declared

\section{Acknowledgements}

The authors would like to thank Prof. Jaroslav Lindner and MUDr. Jaroslav Hlubocký, PhD, from Charles University (Prague, (zech Republic) for providing their opinions and guidance on this research project.

Received on December 8, 2016

Reviewed on March 18, 2017

Accepted on May 12, 2017

DOI

10.17219/acem/73713

\section{Copyright}

Copyright by Author(s)

This is an article distributed under the terms of the

Creative Commons Attribution Non-Commercial License

(http://creativecommons.org/licenses/by-nc-nd/4.0/)

\begin{abstract}
Background. The aim of our experimental work was to assess the impact and morphological changes that arise during different thawing protocols on human aortic valve (AV) leaflets resected from cryopreserved aortic root allografts (CARAs).
\end{abstract}

Objectives. Two thawing protocols were tested: 1. CARAs were thawed at a room temperature $\left(23^{\circ} \mathrm{C}\right)$; 2. CARAs were placed directly into a water bath at a temperature of $37^{\circ} \mathrm{C}$. After all the samples were thawed, non-coronary AV leaflets were sampled from each specimen and fixed in a 4\% formaldehyde solution before they were sent for morphological analysis.

Material and methods. All the samples were washed in distilled water for 5 min and dehydrated in a graded ethanol series $(70 \%, 85 \%, 95 \%$, and $100 \%)$ for 5 min at each level. The tissue samples were then immersed in 100\% hexamethyldisilazane (HMDS) for $10 \mathrm{~min}$, and then air-dried in an exhaust hood at room temperature. Processed samples were mounted on stainless steel stubs and coated with gold. Histological analysis was performed with the use of an electron microscope on a scanning mode operating at $25 \mathrm{kV}$ - BS 301.

Results. Thawing protocol 1 (room temperature at $23^{\circ} \mathrm{C}$ ): $6(100 \%)$ samples showed loss of the endothelial covering of the basal membrane with no damage to the basal lamina. Thawing protocol 2 (water bath at $\left.37^{\circ} \mathrm{C}\right): 5(83 \%)$ samples showed loss of the endothelial covering of the basal membrane with no damage to the basal lamina. One (17\%) sample showed loss of the endothelial covering the basal membrane with significant damage to the basal membrane.

Conclusions. Based on our experimental work, we can clearly conclude that cryopreserved AV leaflet allografts show identical structural changes at different rates of thawing.

Key words: aortic valve, allograft, thawing, cryopreserved, structural changes 


\section{Introduction}

The first allograft transplants in cardiac surgery were freshly harvested aortic valves (AVs). The first fresh AV allograft transplant was performed by Murray in $1956{ }^{1}$ Despite the imperfect hemodynamic outcome of the operation, the allograft performance was outstanding, with perfect leaflet function. Other early experimental and clinical trials, such as Heimbecker, Lam et al. and Kerwin et al., supported the superior properties of fresh AV allografts. ${ }^{2-4}$ Nevertheless, the first successful operation with a patient surviving the fresh AV allograft transplant was performed by Ross in 1962, based on Brewin's experimental work. 5,6

Many cardiac centers started to implement cryopreservation of fresh AV allografts due to the shortage of donors. Cryopreservation of AVs led to a significant decrease of allograft durability, and between the 1960s and the early 1970s this led almost to the abandonment of these types of procedures. ${ }^{7}$ This was primarily due to irreversible damage to cell viability and loss of the structural integrity caused by thawing, resulting in the loss of allograft toughness and elastic properties. ${ }^{8-10}$ Technical advances in tissue handling led to the reintroduction of allograft transplants back into use in cardiac surgery. ${ }^{11}$ To date, there have been no recommended guidelines for cryopreservation and subsequent thawing of cryopreserved allografts that would eliminate damage to the cellular structures.

\section{Material and methods}

\section{Allograft harvest and characteristics}

All the allografts were harvested in the operation theater from patients that were organ donors and were pronounced "clinically dead" in compliance with the transplant laws of the Czech Republic.

Basic allograft characteristics for thawing protocol 1 (thawing at room temperature of $23^{\circ} \mathrm{C}$ ) are summarized in Table 1. Basic allograft characteristics for thawing protocol 2 (thawing in a water bath at $37^{\circ} \mathrm{C}$ ) are summarized in Table 2.

\section{Allograft processing cryopreservation protocol}

All human aortic roots (ARA) underwent an initial decontamination according to the standard protocol of the tissue bank. Afterward, all allografts were stored in an antibiotic cocktail comprised of Cefuroxime $0.2 \mathrm{mg} / \mathrm{mL}$ + Piperacillin $0.2 \mathrm{mg} / \mathrm{mL}+$ Netilmicin $0.1 \mathrm{mg} / \mathrm{mL}$ + Fluconazole $0.1 \mathrm{mg} / \mathrm{mL}$ in the tissue culture nutrient medium E 199 for $24 \mathrm{~h}$ at $37^{\circ} \mathrm{C}$ (Altimed Pharmaceutical, Mississauga, Canada). Subsequently, all ARA were moved into a cryoprotectant solution in a sterile laminar flow
Table 1. Thawing protocol 1 - basic allografts characteristics

\begin{tabular}{|l|c|c|c|}
\hline Gender & $\begin{array}{c}\text { Donor age } \\
\text { [years] }\end{array}$ & $\begin{array}{c}\text { Aorta diameter } \\
{[\mathrm{mm}]}\end{array}$ & $\begin{array}{c}\text { ABO, } \\
\text { Rh compatibility }\end{array}$ \\
\hline Female & 55 & 21 & $\mathrm{~A}+$ \\
\hline Female & 41 & 21 & $\mathrm{~A}+$ \\
\hline Male & 55 & 25 & $\mathrm{AB}+$ \\
\hline Female & 56 & 24 & $\mathrm{~A}+$ \\
\hline Male & 57 & 27 & $\mathrm{~B}+$ \\
\hline Male & 59 & 28 & $\mathrm{O}-$ \\
\hline
\end{tabular}

Table 2. Thawing protocol 2 - basic allografts characteristics

\begin{tabular}{|l|c|c|c|}
\hline Gender & $\begin{array}{c}\text { Donor age } \\
{[\text { years] }}\end{array}$ & $\begin{array}{c}\text { Aorta diameter } \\
{[\mathrm{mm}]}\end{array}$ & $\begin{array}{c}\text { ABO, } \\
\text { Rh compatibility }\end{array}$ \\
\hline Male & 34 & 21 & $\mathrm{~A}-$ \\
\hline Female & 51 & 24 & $\mathrm{~B}+$ \\
\hline Male & 44 & 24 & $\mathrm{~B}+$ \\
\hline Male & 44 & 25 & $\mathrm{O}-$ \\
\hline Male & 42 & 27 & $\mathrm{AB}+$ \\
\hline Female & 37 & 27 & $\mathrm{~A}+$ \\
\hline
\end{tabular}

cabinet; they were packed using a double layer technique (sealed in Gambro Hemofreeze bags; NPBI BV; Gambro, Utrecht, the Netherlands). The cryoprotectant used was $10 \%$ dimethyl sulfoxide in the nutritional source for cell culture E 199. All ARA were then cooled at a controlled rate of $-1{ }^{\circ} \mathrm{C} / \mathrm{min}$ from $10^{\circ} \mathrm{C}$ to $-60^{\circ} \mathrm{C}$, and next rapidly cooled and stored in cryo-containers with a liquid phase of liquid nitrogen at $-196^{\circ} \mathrm{C}$.

\section{Thawing protocols}

Experimental work was based on investigating 12 cryopreserved aortic root allografts (CARAs). They were randomly divided into 2 groups, each group consisting of 6 samples. All allografts were thawed in their original packaging (packed using double layer technique and immersed in 10\% dimethyl sulfoxide). Two thawing protocols were tested:

- protocol 1: 6 human CARAs thawed at room temperature of $23^{\circ} \mathrm{C}$; thawing times were as follows: $\min 2 \mathrm{~h}$ 49 min, $\max 4$ h 5 min (median: 3 h 19 min);

- protocol 2: 6 human CARAs were placed directly into a water bath at $37^{\circ} \mathrm{C}$; thawing times were as follows: min 26 min, max 41 min (median: $32 \mathrm{~min}$ ).

After all the CARAs were thawed, non-coronary AV leaflets were sampled from each specimen and fixated in a $4 \%$ formaldehyde solution before they were sent for morphological analysis. The time variability in both thawing protocols was given by different allografts sizes (Tables 1,2), as well as different amounts of cryoprotectant used for each allograft during the cryopreservation process. 
Table 3. Scoring system for electron microscope sample analysis

\begin{tabular}{c|l} 
Score & \multicolumn{1}{c}{ Morphology } \\
\hline 1 & morphologically intact endothelium - putative physiological changes are not reflected in the superficial morphology of the endothelial cells \\
2 & confluent endothelium with structural inhomogeneity - irregularities in the form of individual cells and changes of their membranes are detectable \\
3 & disruption of intercellular contacts - continuity of the endothelial covering is lost, endotheliocytes shrink while still adhering to the basal membrane \\
\hline 5 & separation of the endothelial cells - endotheliocytes separate from the basal lamina; initially they protrude by their intercellular edges into the lumen \\
\hline 6 & $\begin{array}{l}\text { damage of subendothelial layers - the valvular surface is covered only by the remnants of the basal membrane, the fiber structure of the lamina } \\
\text { fibrosa and the lamina ventricularis may be dissolved }\end{array}$ \\
\hline
\end{tabular}

\section{Microscopic slide preparation}

After the thawing protocols were completed, non-coronary AV leaflets were resected and fixed in Baker's solution. Each sample was divided into 5-10 mm subsamples. In order to prevent artificial mechanical damage to the cellular structures, no mechanical stretching of the samples was performed. All samples were washed in distilled water for $5 \mathrm{~min}$, and dehydrated in a graded ethanol series $(70 \%$, $85 \%, 95 \%$, and $100 \%$ ) for $5 \mathrm{~min}$ at each level. The tissue samples were then immersed in 100\% hexamethyldisilazane (HMDS) (CAS No. 999-97-3; Fluka Chemie AG, Buchs, Switzerland) for $10 \mathrm{~min}$ and air-dried in an exhaust hood at room temperature.

Processed samples were mounted on stainless steel stubs, coated with gold and stored in a desiccator until they were studied and photographed by an electron microscope on scanning mode operating at $25 \mathrm{kV}-\mathrm{BS} 301$. A special scoring system (from 1 to 6 ) was introduced to analyze the morphological changes of the arterial wall of ARA under the electron microscope (Table 3). ${ }^{12}$

\section{Results}

Histological analysis of the ARA arterial wall was as follows: - thawing protocol 1 (thawing at room temperature of $\left.23^{\circ} \mathrm{C}\right): 6(100 \%)$ non-coronary AV leaflets showed loss of the endothelial cells covering the basal membrane with no damage to the basal lamina (score 5) (Fig. 1);

- thawing protocol 2 (water bath at $37^{\circ} \mathrm{C}$ ): 5 (83\%) noncoronary AV leaflets showed loss of the endothelial cells covering the basal membrane with no damage to the basal lamina (score 5); 1 (17\%) non-coronary AV leaflet showed significant damage to the basal membrane (score 6) (Fig. 2).

After further investigation of the samples, it turned out that the severe damage of the non-coronary AV leaflet in thawing protocol 2 was caused by mechanical stresses exerted on the samples during dissection and microscopic sample preparation. The examined sample underwent slight stretching during microscopic slide preparation due to its size. This resulted in more severe structural damage compared to other samples.

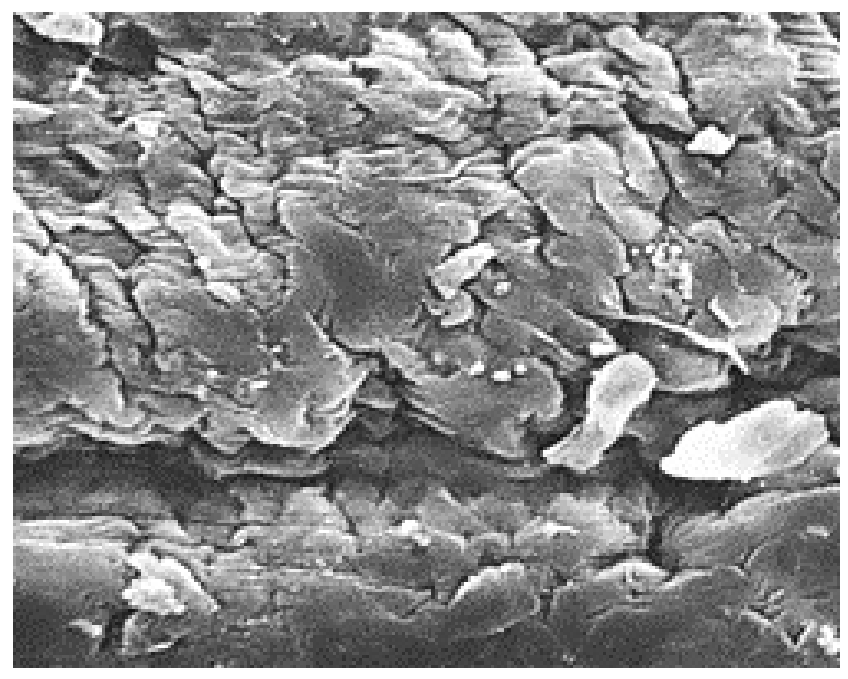

Fig. 1. Non-coronary AV leaflet (magnification: $\times 520)$; thawing at a room temperature $\left(23^{\circ} \mathrm{C}\right)$

AV - aortic valve.

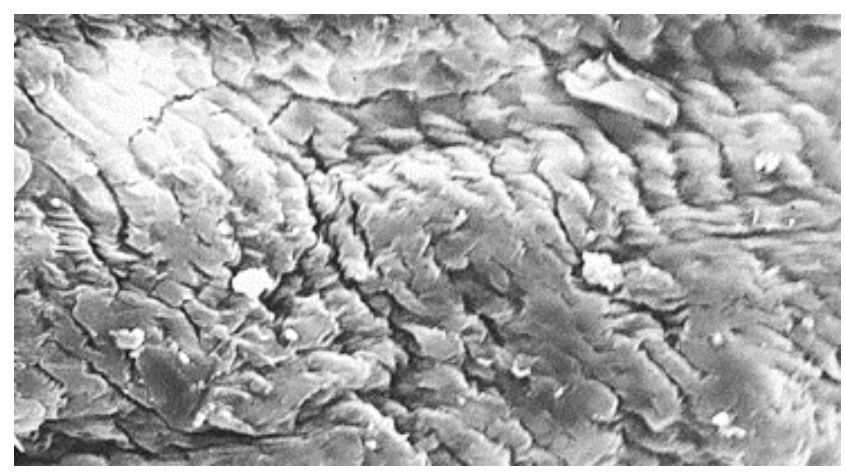

Fig. 2. Non-coronary AV leaflet (magnification: $\times 520$ ); water bath at $37^{\circ} \mathrm{C}$ AV - aortic valve.

\section{Discussion}

Since the first successful AV allograft transplant performed by Ross in 1962, over 25000 AV allografts have been implanted to date. ${ }^{13}$ Over the time, the procedures of sterilization and storage have evolved immensely; from fresh aseptic harvest with immediate transplantation, through antibiotic sterilization and wet storage at $4^{\circ} \mathrm{C}$, up to current antibiotic sterilization and cryopreservation. ${ }^{14}$ Even though the durability 
of fresh AV allografts is superior to cryopreserved AV allografts, the lack of donors has forced most of the cardiac centers to focus on allograft cryopreservation. Cryopreservation plays a major role in the degeneration of AV allografts, which subsequently leads to progressive calcification and fibrosis, affecting up to $1 / 4$ of all implanted AV allografts. ${ }^{13}$ Despite the negative impact of cryopreservation on AV allografts, Fukushima et al. showed that cryopreserved AV allografts were durable for over 15 years. ${ }^{15}$ They also showed that allograft durability was closely associated with and affected by obesity and age of the recipient and donor. The most important factor was the surgical technique used during the allograft transplantation. ${ }^{15}$ Our experimental results show identical structural changes in both examined thawing protocols; therefore, a faster rate of thawing theoretically does not necessarily mean that AV leaflets will be more structurally damaged or compromised; they would not require more frequent observation after implantation.

Another aspect that is thought to contribute to the cryopreserved AV allografts failure is gender mismatch. However, evidence behind this theory is imprecise, as gender matching is not done routinely before such transplants. Böll et al. demonstrated that gender-mismatched vs gendermatched allografts showed no significant difference in regard to death, need for reoperation and allograft function. ${ }^{16}$

Experimental work by Brockbank et al. showed significantly reduced extracellular matrix damage and well-preserved cellular structures in ice-free leaflets. They also demonstrated that cryopreservation of the transplants of the heart valves at $-80^{\circ} \mathrm{C}$ prevents ice formation, and tissue cracking, and preserves extracellular matrix. ${ }^{8,17}$ Improvements in modern antibiotic treatment of AV allografts before cryopreservation have had a significant impact on the infection resistance of AV allografts, as shown in their enhanced bacterial resistance. ${ }^{18}$

The use of cryopreserved allografts has become a gold standard in surgical procedures, such as Ross procedure, or in cases of bacterial endocarditis. However, there is growing evidence that decellularized engineered allografts may be superior to cryopreserved allografts. ${ }^{19}$ Decellularized AV allografts have shown outstanding mid-term results after their implantation in terms of their stable structural integrity, low rate of calcification and hemodynamic properties. ${ }^{20}$ Despite the promising short and mid-term results, long-term results are still not known.

Even though there have been efforts to minimize the damage inflicted by cryopreservation on AV allografts, there are still many factors that need thorough experimental and clinical examination in order to ensure allografts of highest possible quality and durability.

\section{Conclusions}

Our experimental work, based in structural changes occurring during different thawing protocols in cryopreserved AV leaflets, showed that different rates of thawing indicated identical structural changes. Therefore, the rate of thawing does not play a significant role in minimizing structural changes that occur during the thawing of cryopreserved AV leaflets.

\section{References}

1. Murray G. Homologous aortic-valve-segment transplants as surgical treatment for aortic and mitral insufficiency. Angiology. 1956;7(5):466-471.

2. Heimbecker RO. Durability of fresh homograft. Ann Thorac Surg. 1986;42(5):602-603.

3. Lam CR, Aram HH, Munnell ER. An experimental study of aortic valve homografts. Surg Gynecol Obstet. 1952;94(2):129-135.

4. Kerwin AG, Lenkei SC, Wilson DR. Aortic valve homograft in the treatment for aortic and mitral insufficiency. NEng JMed. 1962;266:852-857.

5. Ross DN. Homograft replacement of the aortic valve. Lancet. 1962;2(7254):487.

6. Brewin EG. The use of tissue transplants in the surgery of cardiac valve disease: An experimental study. Guys Hosp Rep. 1956;105(3):328-329.

7. Merin G, McGoon DC. Reoperation after insertion of aortic homograft as a right ventricular outflow tract. Ann Thorac Surg. 1973;16(2):122-126.

8. Brockbank KG, Schenke-Layland K, Greene ED, et al. Ice-free cryopreservation of heart valve allografts: Better extracellular matrix preservation in vivo and preclinical results. Cell Tissue Bank. 2012;13(4):663-671. doi: 10.1007/s10561-011-9288-7

9. Gerson CJ, Elkins RC, Goldstein S, Heacox AE. Structural integrity of collagen and elastin in SynerGraft ${ }^{\circledR}$ decellularized-cryopreserved human heart valves. Cryobiology. 2012;64(1):33-42. doi: 10.1016/j. cryobiol.2011.11.001

10. Moussa M, Dumont F, Perrier-Cornet JM, Gervais P. Cell inactivation and membrane damage after long-term treatments at sub-zero temperature in the supercooled and frozen states. Biotechnol Bioeng. 2008;101(6):1245-1255. doi: 10.1002/bit.21981

11. Jashari R, Van Hoeck B, Ngakam R, Goffin Y, Fan Y. Banking of cryopreserved arterial allografts in Europe: 20 years of operation in the European Homograft Bank (EHB) in Brussels. Cell Tissue Bank. 2013;14(4):589-599. doi: 10.1007/s10561-012-9359-4

12. Krs O, Burkert J, Slízová D, Kobylka P, Špatenka J. Allograft semilunar cardiac valves processing and cryopreservation - morphology in scanning electron microscope. Cell Tissue Bank. 2006;7(3):167-173.

13. Nappi F, Al-Attar N, Spadaccio C, Chello M, Lusini M, Acar C. Aortic valve homograft: 10-year experience. Surg Technol Int. 2014;24:265-272.

14. Heng WL, Albrecht $H$, Chiappini P, Lim YP, Manning L. International heart valve bank survey: A review of processing practices and activity outcomes. J Transplant. 2013;2013:163150. doi: 10.1155/2013/163150

15. Fukushima S, Tesar PJ, Pearse B, et al. Long-term clinical outcomes after aortic valve replacement using cryopreserved aortic allograft. J Thorac Cardiovasc Surg. 2014;148(1):65-72.e2. doi: 10.1016/j. jtcvs.2013.07.038

16. Böll BM, Vogt F, Boulesteix AL, Schmitz C. Gender mismatch in allograft aortic valve surgery. Interact Cardiovasc Thorac Surg. 2015;21(3):329-335. doi: 10.1093/icvts/ivv151

17. Steffen V, Marsch G, Burgwitz K, Kuehn C, Teebken OE. Resistance to infection of long-term cryopreserved human aortic valve allografts. J Thorac Cardiovasc Surg. 2016;151(5):1251-1259. doi: 10.1016/j.jtcvs.2015.11.029

18. Neumann A, Cebotari S, Tudorache I, Haverich A, Sarikouch S. Heart valve engineering: Decellularized allograft matrices in clinical practice. Biomed Tech (Berl). 2013;58(5):453-456. doi: 10.1515/bmt-2012-0115.

19. Tudorache I, Theodoridis K, Baraki H, et al. Decellularized aortic allografts versus pulmonary autografts for aortic valve replacement in the growing sheep model: Haemodynamic and morphological results at 20 months after implantation. Eur J Cardiothorac Surg. 2016;49(4):1228-1238. doi: 10.1093/ejcts/ezv362

20. da Costa FD, Costa AC, Prestes $R$, et al. The early and midterm function of decellularized aortic valve allografts. Ann Thorac Surg. 2010;90(6):1854-1860. doi: 10.1016/j.athoracsur.2010.08.022 